\title{
Tribute to Professor Toshisada Nishida
}

$\operatorname{AUTHOR}(S)$ :

Kayumbo, Hosea

\section{CITATION:}

Kayumbo, Hosea. Tribute to Professor Toshisada Nishida. Pan Africa News 2011, 18(special issue): 5-6

ISSUE DATE:

2011-09

URL:

http://hdl.handle.net/2433/147290

RIGHT:

Copyright (C) Pan Africa News. 
ogy, came to take an active part in the investigation at Mt. Takago.

Let me turn back a little. Nishida-san and I began to collaborate to write books starting in 1972. We worked together to write the "Ecology of Humankind" (Volume 25 of 'The Course of Ecology') of Kyoritsu-Shuppan (collaboration of three people, including Dr. Jiro Tanaka) and in the selection and writing of the items of "animal sociology", "zoogeography", and "human ecology" in the 'Dictionary of Ecology' (Prof. Makoto Numata ed.) of Tsukiji-Shokan. There were three authors of the 'Dictionary of Ecology'; the late Professor Junichiro Itani was the first author, followed by Nishida-san and me. However, we two, Nishida-san and me, came to write it entirely. At one point, we began to meet without the go board to concentrate on writing.

There were various things that I learned from Nishida-san in those days. One was to publish books as well as in journals. First of all, he taught me the importance of conducting original research. We had a strong tendency to put value only on papers at the University of Tokyo, but many people including me came to value the publication of academic books as a result of Nishida-san's influence. Another thing that I learned from Nishida-san is that one's research should make complicated problems easier to understand. This point might reflect, in a sense, a difference in academic traditions between Kyoto University and the University of Tokyo. Anyway, I have always kept this point in mind when collecting data and analyzing them.

While Nishida-san was a Lecturer and an Associate Professor between the 1970's and 1980's, Dr. Tadashi Tanno from the Laboratory of Physical Anthropology at Kyoto University, Dr. Shun Sato, and the late Dr. Satoshi Horai served as research associates in the Department of Anthropology. On the other hand, Harako-san moved to Kyoto University, as mentioned above. All of these personnel changes promoted strong ties between the Laboratory of Physical Anthropology at Kyoto University and the Department of Anthropology and the Department of Human Ecology at the University of Tokyo. Nishida-san kept working hard as a teacher at the University of Tokyo, and as a consequence, there was a surge of interest by students majoring in ecology. Some of them later went on to establish the Association for Ecological Anthropology (The Society for Ecological Anthropology of today).

Finally, let me tell a story about the 11th social gathering of the teachers of the University of Tokyo on February 22, 1988. The president of the University, Wataru Mori, and his special advisor (vice-president) Akito Arima also attended. The theme of the gathering was "Overseas scientific research." Nishida-san talked about his investigations of wild chimpanzees in Africa. I talked about my research on human ecology in Papua New Guinea, and Dr. Masanori Aoyagi of the Faculty of Letters talked about his excavations of archaeological sites of Roman architecture. A campus newsletter at that time described that Nishida-san gave his talk with some touches of humor and that it was received quite well. Thus, Nishida-san left a lasting impact on the development of overseas scientific research at the University of Tokyo, before he left for Kyoto in March.

The end of my recollection is about the game of go, which Nishida-san began to play at the University of Tokyo. We have a lot of lovers of game of go among the members majoring in ecological anthropology in Kyoto

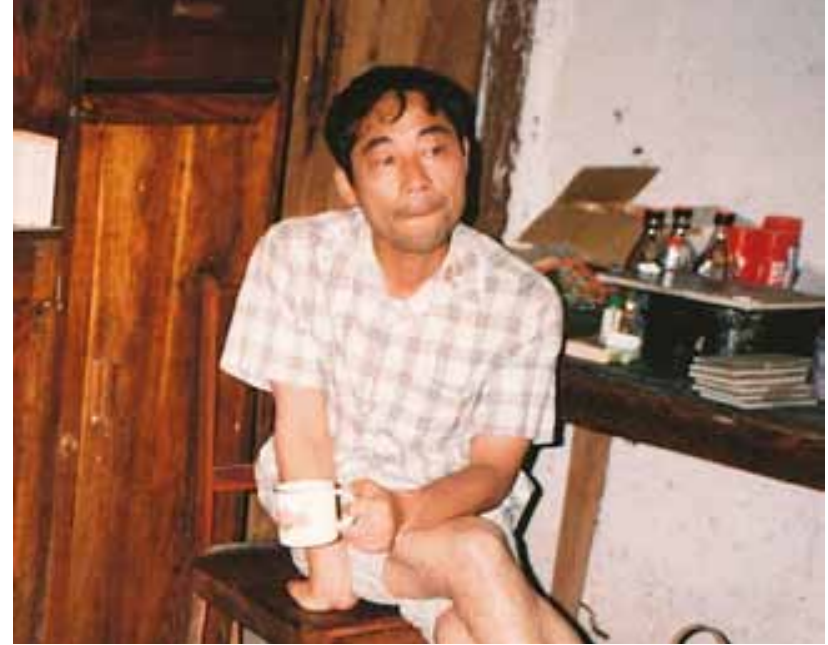

University and the University of Tokyo. We still organize a go tournament twice a year to remember Professor Itani and Harako-san. Of course, Nishida-san was one of the key members. One should be unyielding when playing the game of $g o$, and the unyielding spirit of Nishidasan was considerable. Therefore, it is regrettable that it will not be possible for us to face Nishida-san again at the board. On July 9 this year, we held a "Go tournament in memory of the late Prof. Toshisada Nishida" in Nagoya, and offered condolences in appreciation for his longtime companionship.

Now I put down my pen. On behalf of all his senior and junior colleagues and go companions at the University of Tokyo, I wish to express our sincere gratitude to Nishida-san.

(English translation by Takahisa Matsusaka)

\section{Tribute to Professor Toshisada Nishida}

\author{
Hosea Kayumbo \\ University of Dar es Salaam, Tanzania
}

Professor Toshisada Nishida will be very much missed by staff and students of the Department of Zoology and Wildlife Conservation of the University of Dar es Salaam. He often visited the University of Dar es Salaam on his way to Mahale, Kigoma. He used to interact freely and amicably with staff and students of the Department, to whom he freely gave lectures and conducted seminars. His contributions, however, extend well beyond his role as a mentor.

A quiet but warm, perceptive and acutely intelligent individual, Nishida's lifelong commitment to research on chimpanzees in Africa, stemmed naturally from his interest in people. He particularly emphasised the desirability of engaging with local people. He was very much liked in Mahale. News of his arrival spread quickly throughout the communities living around the National Park. For the field staff who continued to record and collect data while he was in Japan, he would bring many presents - watches, T-shirts, pictures, school books, etc. On one occasion, in August 2001, Professor Kapepwa Tambila, who is from one of the Mahale ethnic (tribes) groups and I accompanied Nishida to Mahale. One evening the local field 
workers and local people from a nearby village organized a ngoma party for us. They ate, danced and drank to celebrate Nishida's arrival. The local people and the Japanese researchers became very excited when Professor Tambila, one of their own, joined the dance and moved about with incredible agility, singing the songs they thought he did not know.

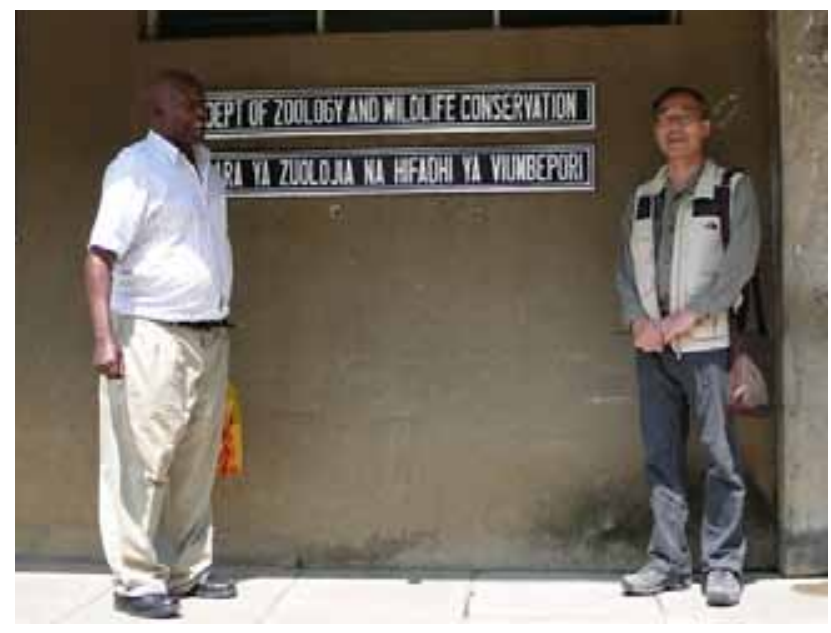

Nishida's concern was not confined to chimpanzees and the threat to their forest habitat. He was very much concerned with the poverty of the local communities living around the Park. He and I therefore thought we could make a small gesture to the local people to indicate that we understood their plight. So in 2000 we decided to build a primary school in one of the neighbouring villages called Katumbi on the shores of Lake Tanganyika. Funds were donated by well-wishers and friends of Mahale in Japan as well as by the Government of Japan. Construction by the villagers themselves started in January 2001 and was completed in May 2002 at a cost of US dollars 32,757. A proposal has now been put forward to add a secondary school and name it Professor Toshisada Nishida School. He once confided in me and said: "You know Kayumbo; in Mahale there is so much to do so few of us to do it, and so little time to do it"

Having worked in Tanzania for more than forty years, Nishida was not worried by the occasional inaccurate reporting of some local newspapers on Mahale, so long as the bounds of good taste and scientific probity were not overstepped.

\section{Nishida-san and Tongwe}

\author{
Makoto Kakeya \\ Professor Emeritus, Kyoto University, Japan
}

In 2011, the year we have suffered an unprecedented earthquake, a tsunami, and an accident at a nuclear power plant, we have lost Nishida-san. He was always concerned about the ongoing destruction of nature and devoted himself to the protection of the great apes. The loss of nature has coincided with an increase in the number of nuclear power plants. I recall the safari when I first visited the Tongwe villages with the late Professor Itani and Nishidasan in 1971; I now think that this time marked the turning point for these changes. At that time, Itani-san was 45 ,
Nishida-san was 30, and I was 26 years old. Forty years after that, Japan's practices to achieve modern civilization have finally led to undermine the life and mind of the Japanese, and Nishida-san passed away.

In 1971, we conducted two safari surveys together. In the first journey, we climbed Mt. Sisaga, one of the main peaks at Mahale, and made a survey of the villages near the Nyenda Plateau in the south-western part of the Tongwe Land. In the second one, we headed to the Mibanga Village to the east of the innermost Nkungwe Bay through the Lwegele River. I remained at the Mibanga Village to continue my research on the nearby villages. Meanwhile, Itani-san and Nishida-san moved further east to Mt. Ipumba and visited the Busungwe Village where people subsisted by hunting large animals. After their visit they enthusiastically related tales about Busungwe, which was really representative of the life of Tongwe people in the depth of the wilderness (which I confirmed myself in a later visit). We experienced many things and unforgettable moments during these safaris. In the first one, we followed the policy of Itani-san who loved to walk at a swinging trot, with minimal food and equipment. In the second safari, Nishida-san was in charge of food. Perhaps because the safari was longer and with more people, he brought along sufficient food, including two chickens. Although Itani-san teased Nishida-san about his "luxurism" compared to his own "minimalism," this may have been the Nishida-style not to trouble inland people about food.

Itani-san and Nishida-san's contrast was also seen in their Swahili language. Itani-san freely used his proper, but not so rich, vocabulary and was a joy to hear. Nishidasan, on the other hand, with his long experience in Tanzania and linguistic talent, spoke fluent Swahili and collected accurate and quantitative information.

I am now keenly aware that I managed to complete my study of the Tongwe people only because of the tutelage of these two quite different individuals. The Tongwe people have supported chimpanzee research and have given us tremendous folk knowledge about the animals and plants at Mahale. As the research went on, we step-bystep gained knowledge about the everyday wisdom, culture, and society of the Tongwe, who lived adaptively in the midst of the wilderness. We have become fascinated by these people and our respect for them became deeper and deeper. It was this sense of respect that bonded the three of us.

Recalling these 40 years, I would like to express my heartfelt condolences to the spirit of Nishida-san.

(English translation by Michio Nakamura)

\section{Short Tribute}

\section{Christophe Boesch}

Max-Planck Institute for Evolutionary Anthropology, Germany

It is with great sadness that I have learned about Professor Toshisada Nishida's death. This announcement brings me back to 1999 when I was with him in the Mahale Mountains comparing the hunting behavior of the chimpanzees with those of the Taï chimpanzees. We stayed for 2 months together in the field and he was kind enough to allow me to share his meals in the evenings. But what made these moments so special were the dis- 